\title{
Análise do discurso e ciência da Informação: aportes teóricos para organização e representação da Informação
}

\author{
Análisis del discurso y ciencia de la información: \\ aportes teóricos para la organización y representación de la información
}

Discourse analysis and Information Science: theoretical contributions to information organization and representation

\section{João Batista Ernesto MorAes, Larissa Mello LIMA, Mariana Silva CAPRIOLI}

\begin{abstract}
Universidade Estadual Paulista, Av. Hygino Muzzi Filho, 737, Campus Universitário, CEP. 17525900, Marília, SP, Brasil;
\end{abstract} prof.joao@gmail.com, larissademellol@gmail.com, mariana.caprioli@gmail.com

\begin{abstract}
Resumen
Se presenta una perspectiva conceptual y teórica de la escuela francesa del análisis del discurso como una metodología complementaria y válida para ser utilizada en estudios teóricos de organización y representación de la información en la Ciencia de la Información. Se seleccionan autores como Foucault (2010 1986), Orlandi (1999) y Mazière (2007) que ofrecen debates fundamentales sobre el Análisis del Discurso. El segundo paso es discutir el tema de la interdisciplinariedad que se centra en las Ciencias de la Información con el fin de fortalecer las bases para el establecimiento de la relación entre el Análisis del Discurso de la escuela francesa y la Ciencia de la información.
\end{abstract}

Palabras clave: Análisis del discurso. Ciencia de la información. Interdisciplinariedad. Escuela francesa de análisis del discurso. Foucault, Michel. Tratamiento temático de la información.

\section{Introdução}

O objetivo deste trabalho reside na apresentação de alguns aportes teóricos que tornam a Análise do Discurso de Matriz Francesa uma metodologia viável de ser utilizada no âmbito da Ciência da Informação para tanto é retomada a relação proposta por Frohmann (1995); Gonzalez-Gomes (2012) entre discurso e documentação, retomando o conceito de regime de informação.

Desta forma, selecionaram-se, primeiramente, os autores Michel Pêcheux, Michel Foucault e Eni Pulcinelli Orlandi que apresentam um panorama conceitual (Foucault, 1986) e discussões fundamentais (Orlandi, 1999), (Henry,1997) (Mazière, 2007) acerca da Análise do Discurso de Matriz Francesa.

Em um segundo momento foi selecionado o autor Pinheiro (1995); (1998) para situar a Ciência da Informação expressando o quanto as estruturas desta estão calcadas na interdisciplinaridade. Tal relação interdisciplinar se torna fundamental para

\begin{abstract}
Is intended to bring a brief overview of the conceptual and theoretical discourse analysis of the French Discourse Analysis as a viable methodology to be used in theoretical studies for representation and information organization within the frame of Information Science. For this, selected authors as Foucault (1985; 2010), Orlandi (1999) and Mazière (2007) were reviewed, who offer fundamental discussions on the French Discourse Analysis. The second step was to discuss the issue of the interdisciplinarity nature of Information Science in order to fortify the bases for the constitution of the relationship between the French Discourse Analysis and Information Science.
\end{abstract}

Keywords: Discourse analysis. Information science. French school of discourse analysis. Foucault, Michel. Subject indexing. Interdisciplinarity.

estabelecer-se o paralelo entra a Análise do Discurso de matriz Francesa e a Ciência da Informação. Em seguida, porém não menos importante, retoma-se os estudos de Frohmann (2001) que realizam um paralelo entre a Análise do discurso e a documentação, caminhando para a perspectiva de materialidade da informação.

Através da categorização das contribuições conceituais que cada um deles elencou, se tornará possível traçar um panorama importante da relação interdisciplinar que a Ciência da Informação possui com a Análise do Discurso de Matriz Francesa retomando por fim pesquisa já desenvolvida no grupo de pesquisa Análise Documentária (Lima, 2015). 


\section{Aportes teóricos da Análise do discurso e Ciência da Informação para Organização e Representação da Informação}

A Análise do Discurso de Matriz Francesa, segundo Foucault (1986), nasce do estruturalismo especulativo que tem bases em trabalhos com matrizes filosóficas e ideológicas, mas vem para modificar essa estrutura, pois visa a compreender o fenômeno da linguagem não concentrado apenas na língua, mas considerando também os elementos que a extrapolam.

Acredita-se ser importante retomar brevemente o contexto histórico pelo qual a França passava para contextualizar os mecanismos que tornaram possível dar importância para os estudos centrados no sujeito da linguagem e por conseguinte, discurso. Michel Pêcheux, filósofo de formação, começa a realizar uma forte ligação entre a Filosofia e as Ciências Sociais a partir de uma série de estudos centrados na língua. (Henry, 1997)

Tal perspectiva se liga com o movimento que começa a irromper na França de negação ao estruturalismo em meados da década de 1960. Buscava combater o excesso de formalismo e padronização dos elementos da linguagem tratados, por influência dos postulados de Saussure, de maneira estrutural.

Em Curso de Linguística Geral Saussure afirma que língua e fala são diferentes, possuindo relação de oposição. Para Saussure a língua é o conjunto de signos estruturados, o todo, que uma comunidade utiliza para se comunicar, ou seja, é algo coletivo e social. Já a fala ele denomina como algo individual, particular, é a maneira como as pessoas usam a língua. Embora diferentes, elas se completam, são dependentes uma da outra. A língua, para que possa existir, se estabelecer, precisa de falantes. Desta maneira, a fala também precisa de um modo para existir, um código, uma ferramenta. Saussure fez seu estudo sobre a língua, pois, segundo ele, era propícia para aprofundamento naquele momento, deixando a fala de lado. (Saussure, 1973)

Ao mesmo tempo em que deixou em segunda plano a fala, Saussure deixa aberto um campo de estudo rico e até então sem aprofundamento teórico.

Ao serem interligados estes fatores listados acima; o excesso de formalismo linguístico somado ao sujeito que conduz a fala sendo deixado em segundo plano, Pêcheux e seus seguidores criam a Análise do Discurso Francesa. O marco inicial da corrente teórica foi fixado no lançamento paralelo em 1969 da obra "Análise Automática do Discurso" de Michel Pêcheux, e da
Revista Langages criada por Jean Dubois. (Gregolin, 1996; Maingueneau, 1997).

Torna-se legítimo afirmar que eles possuíam um solo fértil para germinar teorias centradas no sujeito até então esquecido. Ele retoma, por exemplo, elementos da teoria do inconsciente coletivo de Lacan para dar conta de falar sobre o papel desempenhado pelo sujeito nos discursos.

Além disso são colocados em primeiro plano a questão da ideologia, ele afirma que "a ciência é antes de tudo a ideologia com a qual rompe". Para falar de ideologia ele retoma Louis Althusser, de quem foi aluno e a encara enquanto o que "interpela os indivíduos enquanto sujeitos" (Althusser, 1998), sendo reflexo de uma representação entre a realidade e o sujeito. Seu percurso teórico e metodológico na análise do discurso Francesa é sustentada na pirâmide que busca articular o materialismo histórico com a teoria da ideologia, a linguística focando nos processos de enunciação, e a teoria do discurso que coloca em centro a teoria de determinação histórica dos processos semânticos. (Orlandi, 1999)

A Análise do Discurso, então, trabalha na relação entre o linguístico e o ideológico, na medida em que todo e qualquer discurso sofre a ação da ideologia que o atravessa (Foucault, 1986, p. 56).

[...] Gostaria de mostrar que o discurso não é uma estreita superfície, de contato ou de confronto, entre uma realidade e uma língua, ou intrinsicamente entre um léxico e uma experiência, gostaria de mostrar, por meio de exemplos precisos, que analisando os próprios discursos vemos se desfazerem os laços aparentemente tão fortes entre as palavras e as coisas, e destacar-se um conjunto de regras, próprias da prática discursiva. [...] Não mais tratar os discursos como conjunto de signos (elementos significantes que remetem a conteúdos ou a representações), mas com práticas que formam sistematicamente os objetos de que falam. Certamente os discursos são feitos de signos; mas o que fazem é mais que utilizar esses signos para designar coisas.[...] É esse "mais" que é preciso fazer aparecer e que é preciso descrever.

Foucault, na passagem acima, diz que a questão do discurso ultrapassa o paradigma linguístico alertando que todo discurso reflete uma prática própria. Nesta prática entra a perspectiva ideológica; um dos elementos que formam o "mais" dito por Foucault, ou seja, todo e qualquer discurso sofre a ação da ideologia que o atravessa.

A Análise do Discurso apresenta uma definição extremamente estruturada de Orlandi (1999, p. 15) que se trata:

A Análise de Discurso, como seu próprio nome indica, não trata da língua, não trata da gramática, embora todas essas coisas lhe interessem. Ela trata 
do discurso. E a palavra discurso, etimologicamente, tem em si a ideia de curso, de percurso, de correr por, de movimento. O discurso é assim palavra em movimento, prática de linguagem: com o estudo do discurso observa-se o homem falando.

De tal forma, a autora nos leva a observar que a Análise do Discurso não trabalha com a língua como um sistema abstrato, mas com ela no mundo, significando para o homem que a fala, levando em consideração a produção desses sentidos em suas vidas, enquanto sujeitos ou enquanto membros de uma sociedade.

Entende-se que a linguagem não é um instrumento que se encontra facilmente visível e transparente, por tal motivo a Análise do Discurso procura detectar como um texto significa indo muito além de padrões e de como cada objeto em seu contexto significa. Então a Análise do discurso busca compreender não somente a pratica de linguagem, mas também a parte simbólica e em como isso constrói o ser humano enquanto pessoa. O que leva a refletir que "Consequentemente, o discurso é o lugar em que se pode observar essa relação entre língua e ideologia [...]" (Orlandi, 1999, p. 17).

No que tange ao percurso histórico e evolutivo Da escola francesa da Análise do Discurso é possível citar Foucault e Pêcheux na década de 1970 como precursores na formação do quadro epistemológico da disciplina. Começou-se a delinear neste período as correntes norteadoras da disciplina com M. Pêcheux (1975) e D. Maingueneau. A denominada Escola Francesa de Análise do Discurso possui três fases fundamentais delimitadas por Pêcheux.

Fregonezi (2002, p. 104) retoma Pechêux (1975) e explica que a $A D$ da primeira geração, nos anos 60 e início de 70, procurava colocar em evidência os detalhes de formações discursivas (o discurso comunista, socialista, etc.), considerados como espaços relativamente autossuficientes, apreendidos a partir de seu vocabulário. (Fregonezi, 2002, p. 104). A raiz da Análise do Discurso desta corrente Francesa está no entendimento de que é possível intervir na sociedade por meio e através da linguagem, dando destaque para os então discursos políticos. Na obra de Pêcheux (1983) "Análise Automática do Discurso", a evolução teórica da disciplina é marcada através da categorização de três fases. Na primeira fase AD-1, o corpus de análise era formado por espaços discursivos denominados estáveis e homogêneos: Nesta primeira fase imagina-se que exista um conjunto de enunciados que compõe um discurso idêntico a si mesmo e diferente de outros: o que está contido num discurso está excluído de outro. Por exemplo, o discurso médico é composto de enunciados relativos ao corpo, à saúde. A expressão "o sujeito è assujeitado" pertence a essa fase. (Fregonezi, 2002, p. 82).

É possível perceber que a questão da ideologia afeta e perpassa os ideais desta fase, na medida em que a questão da enunciação é entendida a partir da lógica de que o discurso está submetido a regras específicas que ultrapassam o indivíduo e sua consciência. Ou seja, a dimensão social e histórica orienta as ideias desta fase. $\mathrm{Na}$ segunda fase, a AD-2, Fregonezi (2002) explica que os estudos de Foucault (1985) trouxeram à tona a questão da formação discursiva levando a desconstrução da ideia de homogeneidade das condições de produção. Uma formação discursiva passa a ser caracterizada enquanto dispersão dos enunciados.

A questão do interdiscurso passa a ser elemento que deve ser considerada na constituição de toda análise. Na terceira fase, a AD-3, Pêcheux traz à tona a questão da heterogeneidade discursiva. Neste momento, a polifonia passa a ser discutida na medida em que os enunciados de cada discurso levam a memória de outros discursos (Brandão, 1997, p. 42):

Existe uma negociação entre a heterogeneidade mostrada na linguagem e a heterogeneidade constitutiva da linguagem em que o sujeito, movido pela ilusão de centro, pela ilusão de ser a fonte do discurso, localiza o outro e delimita o seu lugar.

É importante entender a multiplicidade de abordagens que o objeto discurso pode assumir.A vertente centrada nos postulados de Van Dijk (1972), denominada Análise Crítica do Discurso, busca analisar enunciações focando-se nos problemas sociais e mecanismos políticos da atuação discursiva.Pode-se dizer que a escola Francesa da Análise do Discurso e a análise crítica do discurso compartilham o olhar sob a dimensão textual discursiva enquanto uma ruptura com a materialidade linguística.

A abordagem deste trabalho parte da teoria discursiva da Escola Francesa de Análise do Discurso. Pêcheux (1987) refere-se a esta como efeito de sentido entre interlocutores. Retomar Pêcheux e a perspectiva e memória discursiva é, de certa forma, se aliar à perspectiva de Ducrot (1987, p. 94) que em uma de suas hipóteses considera que, para comprender um enunciado, o locutor cumpre "as leis que regulamentam a tomada da palavra na coletividade linguística a que pertence".

Bronckart (2008, p. 90) segue tal linha de pensamento ao entender o locutor como "textualizador". "Instância a qual o autor empírico de um texto confia a responsabilidade sobre aquilo que vai ser enunciado." A partir deste processo o autor explica que são caracterizadas as vozes que 
são expressas no texto, ligando-se assim com a perspectiva de Ducrot ao considerar que os sentidos estão sempre carregados de outros significados.

Perspectiva esta que considera as vozes que são expressas no texto é caracterizada por Maingueneau (2008) como heterogeneidade enunciativa. $\mathrm{O}$ autor retoma a oposição conceitual desenvolvida por J.Authier (2004) "Héterogenéité montrée et hétérogenéite constitutive" . Maingueneau (2008, p. 31) explica o primeiro exemplo do seguinte modo:

[...] É acessível aos aparelhos linguísticos, na medida em que permite apreender sequências delimitadas que mostram claramente sua alteridade [...]

Esta citação direta é um exemplo de heterogeneidade mostrada pois se trata de uma sequência linguística em que é marcada de forma explícita a presença de outro locutor no texto. Já a heterogeneidade constitutiva acontece quando há uma sequência linguística marcada de forma implícita na podem ser apreendidas por uma abordagem linguística stricto sensu.

$\mathrm{Na}$ heterogeneidade constitutiva se encontra o interdiscurso, no sentido em que amarra o Mesmo do discurso e seu Outro, sendo uma relação intrincada (Maingueneau, 2008). Assim, os discursos são colocados em relação com outros, posteriormente, não existindo juntos previamente, ou seja, nascem nessa brecha da rede interdiscursiva.

O interdiscurso possuem uma relação de consonância com os processos de enunciação que segundo Pêcheux e Fuchs (1975, p. 176) "consistem em uma série de determinações sucessivas pelas quais o enunciado se constitui pouco a pouco e que tem como característica colocar o 'dito' e em conseqüência rejeitar o 'não-dito'."

Pêcheux e Fuchs (1975, p. 176) explicam ainda que o processo da enunciação e formado por fronteiras que situam o que é dito em um campo criado pelo enunciador buscando validar o seu dizer, ou seja, buscando ter domínio do sentido. Este fenômeno é conhecido como esquecimento numero 2:

A enunciacao equivale pois a colocar fronteiras entre o que foi "selecionado" e tornado preciso aos poucos atraves do que se constitui o "universo do discurso", e o que é rejeitado. Desse modo se acha, pois, desenhado num espaço vazio o campo de "tudo o que teria sido possivel ao sujeito dizer (mas que nao diz)" ou o campo de "tudo a que se opoe o que o sujeito disse". Esta zona do "rejeitado" pode estar mais ou menos proxima da consciencia e ha questoes do interlocutor - visando a fazer,por exe$\mathrm{mplo}$, com que o sujeito indique com precisao "o que ele queria dizer" - que o fazem reformular as fronteiras e re-investigar esta zona. Propomos chamar este efeito de ocultaçao parcial esquecimento $n 2 \mathrm{e}$ de identificar a a fonte da impressao de realidade do pensamento para o sujeito ("eu sei o que eu digo", "eu sei do que eu falo").

Movimento inverso é denominado como esquecimento numero 1 (Pêcheux \& Fuchs, 1975, p. 176):

Por oposiçao, o esquecimento $n$ 1, cuja zona é inacessível ao sujeito, precisamente por esta razao, aparece como constitutivo da subjetividade na lingua. Desta maneira, pode-se adiantar que este recalque (tendo ao mesmo tempo como objeto o proprio processo discursivo e o interdiscurso, ao qual ele se articula por relacoes de contradicao, de submissão ou de usurpacao) é de natureza inconsciente, no sentido em que a ideologia é constitutivamente inconsciente dela mesma.

Entende-se assim que o esquecimento numero 1 é aquele de natureza inconsciente e sendo assim propriamente ideológica, tendo a ideia ilusória de ser centro de origem do sentido. Situar o processo ideológico na análise é falar sobre formação ideológica que segundo os referidos autores são os elementos externos à formação discursiva que repousam nas relações de poder.

\subsection{Ciência da Informação}

e interdisciplinaridade

Um ponto importante a ser tratado é a conceituação da Ciência da Informação, uma vez que se trata da ciência que usa a informação como objeto de estudo, ou seja (Pinheiro e Loureiro, 1995, p. 2):

[...] ciência da informação é aquela disciplina que investiga as propriedades e o comportamento da informação, as forças que governam o fluxo da informação e os meios de processamento para acesso e uso otimizados. Ela diz respeito àquele corpo de conhecimento ligado à origem, coleta, organização, armazenagem, recuperação, interpretação, transmissão, transformação e utilização da informação... possui um comportamento de ciência pura, que investiga o interior do assunto sem considerar suas aplicações, é um componente de ciência aplicada, que desenvolve serviços e produtos.

Uma das primeiras definições de C.I., exatamente essa: "disciplina que investiga as propriedades e comportamento da informação, as forças que regem o fluxo de informação, a fim de alcanças acessibilidade e utilização ótimas", definição dada por Taylor em 1966 e posteriormente sintetizada por Borko, em 1968.

A C.I. é amplamente conhecida como interdisciplinar por nascença, sendo impossível, desde o seu surgimento, estudá-la como algo isolado, sabendo que a todo o momento existe diálogo entre 
ela e alguma outra área do conhecimento, e por tanto, acaba se tornando uma área mais rica.

Segundo Pinheiro (1998, p. 133):

Durante vinte anos de estudos de Ciência da Informação, nossa percepção é de que a Ciência da Informação tem seu próprio estatuto cientifico como ciência social que é, portanto, interdisciplinar por natureza, e apresente interfaces com a Biblioteconomia, Ciência da Computação, Ciência Cognitiva, Sociologia da Ciência e Comunicação, entre outras áreas, e suas raízes, em principio, vem da bifurcação da Documentação/Bibliografia e da Recuperação da Informação. E seu objeto de estudo, por si mesmo, na complexidade de categoria abstrata, é de difícil apreensão.

A existência da interdisciplinaridade se dá pela relação de constante troca que executa com outras disciplinas, essas trocas precisam ser teóricas e metodológicas sendo importante e indispensável a clareza para identificar onde ocorre 0 encontro das duas áreas do conhecimento que se relacionam. Segundo Le Coadic (1996), uma série de temas periféricos que se apoiam firmemente na C.I. se destacam, como temas psicológicos, relacionados a comportamento de comunicação, por exemplo, ou linguísticos como a semiótica, e sociológicos como a produtividade cientifica, entre outros.

Ainda existem definições que sugerem relações interdisciplinares implícitas, pois a C.I. é uma

[...] disciplina que surge de uma fertilização cruzada de ideias que incluem a velha arte da Biblioteconomia, a nova arte da Computação, as artes dos novos meios de comunicação, e aquelas ciências como a Psicologia e Linguística, que em suas formas modernas têm a ver diretamente com todos os problemas da comunicação - a transferência do pensamento organizado. (PINHEIRO, 1998, p. 135).

A partir das discussões que tangenciam a questão da interdisciplinaridade na Ciência da Informação torna-se importante considerar a perspectiva de transdisciplinaridade na Análise Documental de conteúdo (Garcia Marco, 1998; Izquierdo Arroyo, 1993; Gonzalez de Gomes, 1990) na medida em que adentrar na questão da transdisciplinaridade é delimitar ainda mais a preocupação com a formação de um quadro teórico para abarcar a multiplicidade de abordagens teóricas e metodológicas da área. Caracterizam como "momentos históricos sucessivos no programa de sistematização científica" (Sagredo Fernández e Izquierdo Arroyo, 1983, p. 24) os níveis de interação disciplinar em que estão a interdisciplinaridade e transdisciplinaridade.

A questão da transdisciplinaridade se sustenta na discussão dos sistemas complexos (complexidade) que seriam aqueles que possuem uma série de componentes interagindo de maneiras diversas.

Já a integração de conhecimentos interdisciplinar baseia-se no diálogo entre conceitos e disciplinas na medida em que os mesmos são apropriados e transformados no âmbito de determinado contexto disciplinar.

O contexto disciplinar base deste artigo parte da Ciência da Informação diante da interdisciplinaridade, sendo apresentada a Análise do Discurso como uma metodologia viável, e para tanto, viável contextualização no âmbito da Ciência da Informação. Exemplifica-se o quanto suas estruturas são impregnadas de interdisciplinaridade para se compreender, posteriormente, a relação com a Análise do Discurso.

\subsection{Foucault e as formações discursivas}

Foucault (1986) diz que a questão do discurso transcende o paradigma linguístico alertando que todo discurso reflete uma prática própria. Nesta prática entra a perspectiva ideológica; um dos elementos que formam o "mais" dito por Foucault, ou seja, todo e qualquer discurso sofre a ação da ideologia que o atravessa.

Ligar o linguístico e o ideológico, no âmbito da prática discursiva, é falar de formação discursiva na medida em que esta determina o que pode ou não ser dito em certo campo do conhecimento levando em conta a posição do enunciador.

Em relação à perspectiva de repetição Foucault (2010, p. 23) alerta:

Não há de um lado, a categoria dada de uma vez por todas dos discursos fundamentais ou criadores; e, de outro, a massa daqueles que repetem, glosam e comentam. Muitos textos maiores se confundem e desaparecem, e por vezes comentários vêm tomar o primeiro lugar. Mas embora seus pontos de aplicação possam mudar, a função permanece; e o princípio de um deslocamento encontra-se sem cessar reposto em jogo. (Foucault, 2010, p. 23).

Interligar a perspectiva de formação discursiva com gênero discursivo se torna importante sob tal perspectiva na medida em que o gênero do discursivo científico possui características singulares.

Guimarães (2001) nos explica acima é que o discurso científico é mais fechado, finalizado em si mesmo na medida em que o enunciador leva em conta um viés para se comunicar com o enunciatário que nesse caso são os pares da comunidade científica. No que tange à complexidade das relações enunciativas nessa esfera, Barros (2014, p. 167) expõe que: 
[...] ponderação fundamental a respeito do discurso científico é que ele é acima de tudo, polifônico e representado. Quer dizer as relações enunciativas serão profundamente complexas e irão se estabelecer em camadas.

A questão da polifonia se explica no fato do discurso científico ser formado por várias vozes que se relacionam no texto além da do autor.

Estas várias vozes que se relacionam e atestam o discurso científico são explicadas por Bakhtin (2003, p. 281) através do fato de que todos os gêneros do discurso são encarados a partir da marca da heterogeneidade. Ao que parece o discurso científico apresenta uma marca mais expressiva desta heterogeneidade na medida em que:

Os gêneros secundários do discurso - o romance, o teatro, o discurso científico, o discurso ideológico - aparecem em circunstâncias de uma comunicação cultural mais complexa e relativamente mais evoluída, principalmente escrita: artística científica, sociopolítica. Durante o processo de sua formação, esses gêneros secundários absorvem e transmutam os gêneros primários (simples) de todas as espécies, que se constituíram em circunstâncias de uma comunicação verbal espontânea.

Ao descrever o processo de formação do discurso científico, é ressaltado o quanto este enquanto gênero secundário é complexo por ser formado e atestado pelos gêneros primários. Acredita-se que aconteça um fenômeno de engessamento na medida em que a camada da comunicação científica segue regras e padrões argumentativos.

Desta forma, devido a essas características, pode-se compreender que o discurso científico, no qual a Ciência da Informação repousa, existe uma constante redefinição e repetição de posturas anteriores e de deslocamentos provocados pela ação do poder (instituições de pesquisa, pesquisadores, agências de fomento, universidades).

É parte do próprio movimento de validação científica a questão da repetição na medida em que um autor $X$ de menor "impacto" cita autor $Y$ de maior impacto e reconhecido pela comunidade científica (poder) o autor $X$ busca filiar-se ao ponto de "superar" o autor $Y$, desta forma é possível dizer que a prática científica é refém de suas formulações enunciativas.

Em pesquisa desenvolvida, Lima (2015) caracterizou a presença de duas formações discursivas incidindo sobre a área no Brasil:

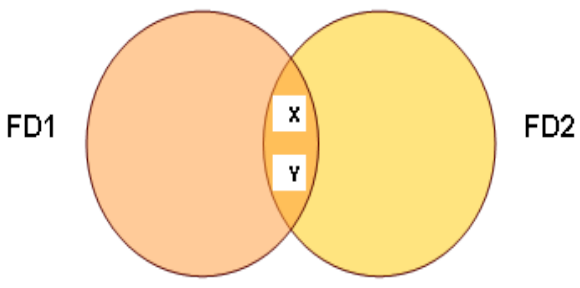

$X:$ IBICT (IBBD)
Y: CNPQIFGV

Figura 1. Formações discursivas da Ciência da Informação

Como formação discursiva 1 (FD1) há a caracterização da Ciência da Informação a partir de sua interdisciplinaridade. Como formação discursiva 2 (FD2) há o entendimento de que a Ciência da Informação é uma disciplina recente que carece de balizas teóricas.

No ponto de intersecção entre ambas as formações discursivas $(X ; Y)$ temos o IBICT e o $\mathrm{CNPq} / \mathrm{FGV}$. O Instituto Brasileiro de Bibliografia e Documentação (IBBD atual Instituto Brasileiro de Informação Científica e Tecnológica; IBICT) foi criado em 1956, como uma iniciativa da Unesco IBBD que sugeriu à fundação Getúlio Vargas (FGV) que promovesse no Brasil a criação de um centro nacional de bibliografia tendo como foco o intercâmbio de documentações técnico científica valorizando a perspectiva tecnológica.

Acredita-se que tais órgãos se configuram como instâncias de validação científica da Ciência da Informação no Brasil, na medida em que segundo Menezes, Silva e Couzinet (2007) o IBBD foi o órgão responsável pela criação de periódicos de importância norteadora para a área em âmbito Nacional; Ciência da Informação e Revista da Escola de Biblioteconomia da UFMG. Este fato não pode ser desvinculado do fato do IBBD ter implementado no país dois anos antes, em 1970, o primeiro curso de mestrado em Ciência da Informação.

O IBBD possui relação direta com o CNPq (Centro Nacional de Desenvolvimento Científico e Tecnológico) e a FGV (Fundação Getúlio Vargas) na medida em que estas se configuram como entidades governamentais específicas para fomentar o desenvolvimento científico no Brasil. Ou seja, são fatores que dentro de uma conjuntura histórico discursiva formam a perspectiva de institucionalização da área. 
Interligar a perspectiva institucional com a discursiva, por meio da prática caracterização das formações discursivas (FD1); (FD2), é se ater ao conceito de "Regime de Informação". Frohmann (1995) sinaliza para o fato de como a informação é materializada através do meio institucional

A partir de Frohmann (1995) González de Gómez (2012) pontua que a criação do então IBBD, atual $\mathrm{IBICT}$, indicou o surgimento de um novo regime de informação no Brasil, uma vez que sua criação foi oriunda de uma parceria da Unesco com a Fundação Getúlio Vargas, por intermédio de seu representante no Brasil, Paulo Carneiro, o qual indicou Lydia de Queiroz Sambaquy, juntamente com Jannice Monte-Mór, para percorrerem as principais bibliotecas e centros de documentação da Europa e Estados Unidos durante quase um ano, viagem essa, que tinha a finalidade de fomentar o estabelecimento de centros bibliográficos nacionais, se beneficiando da política da Unesco.

Tal ação contou com o apoio da Fundação Getúlio Vargas e serviu para ampliar as ideias de Lygia de Queiroz Sambaquy sobre a estruturação que um órgão que fosse dedicado a trabalhos bibliográficos deveria possuir para impulsionar atividades cientificas e tecnológicas do país. Tal criação confirma a teoria de regime de informação, que se trata de:

Um regime de informação seria o modo informacional dominante em uma formação social, o qual define quem são os sujeitos, as organizações, as regras e as autoridades informacionais e quais os meios e os recursos preferenciais de informação, os padrões de excelência e os modelos de sua organização, interação e distribuição, enquanto vigentes em certo tempo, lugar e circunstância (Gonzales de Gomez, 2012).

É possível pontuar, a partir das considerações acima, que o conceito de Regime de Informação de Frohmann (1995) relaciona a perspectiva institucional com a discursiva via a relação entre formações discursivas. Ela torna possível a compreensão das instâncias de validação científica da Ciência da Informação no Brasil situadas enquanto atores que relacionam dinâmicas de poder da área no país.

\subsection{Mazière e Orlandi: Dispositivo de observação da Análise do Discurso}

Utilizar a Análise do Discurso enquanto metodologia de pesquisa é trabalhar na construção de um dispositivo de observação (Mazière, 2007).

O referido autor explica que o discurso para o analista do discurso se configura como produto, na medida em que há a materialidade do enunciado ou de um grupo de enunciados que formam a "corpora" que será submetida à análise.

Mazière (2007, p. 14), além disso, destaca o papel do analista do discurso dizendo que "ele delimita, põe em correspondência, organiza fragmentos de enunciados, mais ou menos longos e mais ou menos homogêneos para submetê-los à análise."

Para formar este "dispositivo de observação" é necessário se atentar para elementos que interferem na produção de todo e qualquer discurso. Orlandi (1999) explica que a Análise do Discurso possui um estatuto histórico próprio, possuindo contribuições paralelas de J. Dubois e M. Pêcheux, dois nomes configurados como polos na vertente francesa da Análise do Discurso.

Do lado de J. Dubois, a instituição da Análise do Discurso é pensada dentro de um continuum: a passagem do estudo das palavras (lexicologia) ao estudo do enunciado é "natural", é uma extensão, um progresso permitido pelo linguista. A $A D$, em suma, não terá sido senão um lance de seu caminho científico. Do lado de M. Pêcheux, ao contrário, a Análise do Discurso é pensada como ruptura epistemológica com a ideologia que domina nas ciências humanas. (especialmente a psicologia) (Orlandi, 1999, p. 18).

O "continuum" de Dubois que faz a Análise do Discurso um reflexo do percurso da linguística, pode ser encarada como uma tentativa de "dominação" por parte deste teórico, no sentido de que se busca enquadrá-la em uma naturalidade extensiva.

Já Pêcheux representa a "resistência" a esta perspectiva na medida em que enxerga a Análise do Discurso sob a ótica do rompimento com a ideologia das Ciências Humanas.

Orlandi (1999, p. 15) diz que o interesse de estudiosos na linguagem de maneira particular com base nas diversas formas de significar, preconizou a origem da Análise do Discurso.

Assim, a primeira coisa a se observar é que a análise do discurso não trabalha com a língua enquanto um sistema abstrato, mas com a língua no mundo, com as maneiras de significar, com homens falando, considerando a produção de sentidos enquanto parte de suas vidas, seja enquanto sujeitos, seja enquanto membros de uma determinada forma de sociedade.

Ou seja, sai do foco a esfera da língua como elemento neutro para a visão de que a linguagem enquanto discurso não é neutra. 
Orlandi (1999, p. 19) define o quadro epistemológico da Análise do Discurso relacionando três regiões do conhecimento científico:

- o materialismo histórico, como teoria das formações sociais e suas transformações.

- a linguística, como teoria dos mecanismos sintáticos e dos processos de enunciação.

- a teoria do discurso, como teoria da determinação histórica dos processos semânticos.

Ou seja, a linguagem é dotada de uma materialidade. Dentro desta materialidade está inserido o falante, sujeito parte das formações e transformações sociais, os atos deste falante possuem uma semântica e, por conseguinte fazem parte de um processo histórico.

Mapear o discurso dos sujeitos que atuam em uma ciência é levar em consideração estes elementos que se movimentam em relação à posição de cada enunciado.

\subsection{Paralelo entre Análise do Discurso e Ciência da Informação}

Ao falar-se da Ciência da Informação e conceitos importantes da Análise do Discurso de matriz francesa, encontra-se a necessidade de relacionar as duas, uma vez que esse trabalho visa a situar a Análise do Discurso na Ciência da Informação, e dessa forma, a pergunta que surge é: $\mathrm{O}$ que ambas tem em comum ou como conversam? Para Cordeiro (2004, p. 85):

Análise de Discurso e Ciência da Informação evoluem a partir dos anos 1960 seguindo caminhos semelhantes se consideradas, ambas, como expressão de uma face da ciência pós-moderna. A partir do pós- Guerra, apresentam crises que são comparáveis e em sincronia, apresentam trânsitos por várias espaços epistemológicos: do paradigma físico, ao paradigma cognitivo, daí ao social. Assim se descreve os passos da $\mathrm{Cl}$. Se bem que há quem diga que os modelos dos paradigmas já não se aplicam mais. Nem mesmo a epistemologia teria aplicação tão efetiva se comparada à arqueologia do saber.

No que tange a perspectiva de pós modernidade, o paradigma físico citado por Cordeiro (2004) pode ser exemplificado.

Então, tem-se que a Ciência da Informação e Análise do Discurso seguiram caminhos paralelos ou parecidos, considerando de onde são oriundas. Belkin e Robertson (1976) citados por Freire (1995) mostram que a primeira é constituída por um conjunto ou coleção de signos que foram estruturados de tal forma propositalmente ou propositadamente por um emissor que tem a intenção de mudar a imagem para o receptor, ou seja, se pensa em como o emissor pode estruturar seus pensamentos para que o receptor seja capaz de perceber a mensagem que o emissor desejava passar. O que se torna semelhante com o que a Análise do Discurso se propõe a realizar enquanto metodologia de pesquisa, na medida em que ela trata a linguagem levando em conta a ideologia que incide durante todo o processo histórico que é também propriamente discursivo. Ou seja, se preocupando como a língua como algo concreto, em como ela significa no mundo levando em consideração a produção de sentido enquanto parte na vida dos homens na qualidade de sujeitos ou membros de uma sociedade, mostrando, dessa forma, que a linguagem não é neutra e leva em consideração emissor, receptor e contexto.

Viu-se a necessidade de diferenciar os conceitos de Análise de Conteúdo e de Análise Documental de Conteúdo, além de Análise do Discurso, a fim de verificar a diferença presente entre elas, embora sejam de fato tão próximas. Dessa forma,segundo Bardin (1997) a Análise de Conteúdo se trata de um método de organização e análise dos dados, e para tanto, deve possuir algumas características como se aceitar que o seu foco seja na qualificação de vivências de um sujeito, assim como suas preocupações sobre determinado objeto e seus fenômenos. Ainda segundo Bardin, é constituída por várias técnicas na qual se busca descrever o conteúdo emitido no processo de comunicação, sendo por meio de falas ou de textos, técnicas essas, compostas por procedimentos sistemáticos que levam ao levantamento de indicadores, podendo ou não ser quantitativos, e permitindo a realização de inferências de conhecimentos.

A principal diferença entre a Análise de Conteúdo e a Análise do Discurso, é que não compartilham do mesmo horizonte teórico, nem pressuposto metodológico de que a produção linguística seria reveladora de opiniões e de crenças de um sujeito em relação ao mundo que o rodeia, uma vez que na Análise do Discurso não se pode negligenciar as relações de um texto e seu entorno e, segundo Charaudeau e Maingueneau (2004), deve-se visar predominantemente o modo como a enunciação é capaz de inter-relacionar uma organização textual e um lugar social determinado.

Da mesma forma, também se diferencia de Análise Documental de Conteúdo, que "(...) ao lado da catalogação de assunto e da indexação, uma das correntes teóricas que historicamente permeia a Organização do Conhecimento no âmbito do Tratamento Temático da Informação" (guimarães, 2008, 2009). Esse tipo de Análise Documental foi ao longo de duas décadas, e con- 
tinua sendo, amplamente empregada na Espanha, possuindo clareza de situação de referência teórica.

Vale ressaltar que, segundo Pinto Molina (1992) e Ruiz Pérez (1992), diferentementente do Brasil ou da França que se utilizam da Análise Documental para o tratamento temático da informação (dimensão de conteúdo), na Espanha a expressão se tratra de uma definição mais abrangente enquanto Tratamento da Informação, se dividindo entre: Análise documental de forma (ADF) e Análise documental de conteúdo (ADC).

Realiza-se nesse momento um breve trajeto do cenário Francófono que abarca de maneira efetiva a ligação entre a Análise Documental de conteúdo e a Análise do Discurso a partir do viès da corrente francesa da pragmática, lingüística textual que culminaram na aplicação das teorías do resumo documental dentro da Análise Documental de Conteúdo. (Izquierdo Alonso e Moreno Fernández, 2009).

A questão da Análise Documental, segundo Guimarães e Sales (2010), encontra bases na tradição Francófona, onde se constata que a construção do conceito de Documentação parte-se das idéias de Paul Otlet (1934), e é nesse contexto que se destaca o papel dos autores como José López Yepes, Izquierdo Arroyo e Felix Sagredo, que introduziram a concepção francesa de documentação no universo biblioteconômico espanhol.

Dessa forma, Sagredo Fernández e Izquierdo Arroyo (1982) realizam um histórico sobre a noção de documento focando no avanço tanto semântico quanto etimológico próprio do termo. Termo para os referidos autores é conceito chave para definir documento na medida em que consideram o documento como palabra (termo) e também como objetivo (entidade).

No contexto da Análise do discurso o documento se enquadra na perspectiva construtiva funcional pois esta destaca a função do documento no que diz respeito aos fundamentos do modelo de comunição humana que são: Emissão, Recector, mensagem, código, canal, ruído e contexto em que se insere todo esse proceso, ou seja, reflexo de qual formação discursiva e ideológica.

Segundo Izquierdo Alonso (2000) a pragmática documental coloca em relação um elemento lingüístico com seus autores e receptores. Estes em uma situação de comunicação documental concreta e específica. Nesta dimensão é destacada a importancia de adequar a representação do conteúdo ao contexto, retomar o contexto é propriamente discursivo entendendo a língua enquanto elemento concreto, que dá significado e produz sentido.

Segundo Serres (s.d.) e Chaumier (1982), citados por Guimarães et al (2012, p. 47), nessa área

[...] estudos de forte matriz lógico-linguística foram desenvolvidos, no intuito de melhor compreender como se processa a operação intelectual de representação do conteúdo de um documento de tal modo a propiciar uma consulta e uma recuperação mais efetivas, por meio de produtos oriundos da condensação (tais como resumos) e da indexação (tais como conceitos-chave de conteúdo).

No Brasil, partido de bases Francesas, bem como 0 cenário Francófono Espanhol apresentado, a Ciência da Informação se articula na tríade produção, organização e uso da informação, segundo Guimarães (2008), e a organização da informação se importa com a representação da informação, justifica-se a Análise do Discurso como parte da Análise Documental e "[...] apresenta um conjunto de procedimentos metodológicos voltados à definição do conteúdo temático de documentos de modo a permitir a recuperação, o acesso e o uso da informação neles contida" (Moraes, 2011).

Sendo assim é importante pontuar, primeiramente, que a principal diferença entre análise do discurso e análise de conteúdo está no fato de que a segunda se importa com o que está sendo dito enquanto que para a primeira, interessa o como está sendo dito, ou seja, quais são as filiações teóricas e institucionais que possibilitam aquele dizer. Já a análise documental de conteúdo e a análise documental de forma se caracterizam, segundo (Guimarães, 2008) a partir da diferenciação que coloca a análise documental de forma como a que se preocupa com "os elementos de natureza material do documento" (Guimarães, 2008, p. 198), e a análise documental de conteúdo se preocupa com "os elementos de natureza intelectual do documento." (Guimarães, 2008, p. 198). o referido autor nos explica que estas dimensões de análise são realizadas de maneira consecutiva caracterizando assim a natureza cognitiva que incide sobre os processos.

\section{Considerações finais}

Retomadas as discussões propostas por Foucault (1986; 2010), Orlandi (1999), Pinheiro (1998) e Cordeiro (2004) é possível dizer que a Análise do discurso de matriz francesa apresenta uma metodologia viável de utilização nos estudos da área, sendo então a Ciência da Informação uma ciência interdisciplinar, a qual se relaciona com diversas outras ciências. recorda-se que a 
análise do discurso e a ciência da informação se preocupam com a forma que a informação será recebida a partir de um emissor e em determinado contexto. além disso, a partir da interação entre a perspectiva institucional com a discursiva foi elucidada a importância do regime de informação (frohmann, 1995; gonzález-gomez, 2012) no tessitura do impacto da análise do discurso na documentação.

Ou seja, pode-se dizer que a utilização justificase através do fato de que a Análise do Discurso articula ferramentas que visam não apenas situar o dito mas relacioná-lo às dinâmicas de poder, perspectiva que tem o potencial de trazer um novo viés para os estudos sobre representação e organização da informação na área.

llustrou-se de maneira pontual tal viés através da caracterização das instâncias de validação científica da área no Brasil permitindo a visualização da conjuntura histórico-discursiva que formam a institucionalização da Ciência da Informação no Brasil.

\section{Referências}

Althusser, L. P. (1998). Aparelhos Ideológicos de Estado. $7^{\text {a }}$ ed. Rio de Janeiro: Graal, 1998.

Bardin, L. (1977). Análise de conteúdo. Lisboa: Edições 70 Ltda, 1977.

Bakhtin, M. (2003). Estética da criação verbal. São Paulo: Martins Fontes, 2003.

Brandão, N. H. H. (20014). Introdução a análise do discurso. 2.ed. campinas: ed. da unicamp, 2004.

Barros, T. H. B. (2014). A representação da informação Arquivística: Uma Análise do discurso teórico e institucional a partir dos contextos Espanhol, Canadense e Brasileiro. Marília: Unesp.Tesis Doctoral.

Bronckart, J. P. (2008). O agir nos discursos: das concepções teóricas às concepções dos trabalhadores. Campinas: Mercado de Letras, 2008.

Cavalcante, R. B; Calixto, P; Pinheiro, M. M. K. (2014). Análise de conteúdo: considerações gerais, relações com a pergunta de pesquisa, possibilidades e limitações do método. // Inf. \& Soc. 24:1, (abr 2014).

Charaudeau, P.; Maingueneau, D. (2004). Dicionário de Análise do Discurso. São Paulo: Contexto, 2004.

Cordeiro, P. A. (2004). Análise do discurso e ciência da informação: Ensaio sobre uma possibilidade metodológica. Rio de Janeiro: UFRJ. Dissertação. http://www.cprm.gov .br/publique/media/mestrado_pedro.pdf (2013-12-03).

Ducrot, O. (1987). O dizer e o dito. Campinas: Pontes, 1987.

Freire, I. M. (1995). Informação; consciência possível; campo. Um exercício com construtos teóricos. // Ci. Inf. Brasília. 24:1 (fev 1995).

Fregonezi, J. A. (2002). "Que casô era pro resto da vida, né?": Um olhar feminino: o processo discurso/memória. Londrina: Edições Humanidades, 2002.

Frohmann, B. (1995). Taking information policy beyond information science: applying the actor network theory. // 23rdAnnual Conference: Canadian Association form Information, 1995.

Foucault, M. (1986). A arqueologia do saber. Rio de Janeiro: Forense, 1986
Foucault, M. (2010). A ordem do discurso. São paulo: Edições Loyola, 2010.

García Marco, F. J. (1998). El concepto de información: una aproximación transdisciplinar. // Revista geneneral de información y documentación. 8:1.

Gonzalez de Gomez, M. N. (1990). O objeto de estudo da Ciência da Informação : paradoxos e desafios. // Ciência da Informação. 19:2 (dez.1990)

Gonzalez de Gomez, M. N. (2012). Regime de informação: construção de um conceito. // Informação \& Sociedade. 22: 3 (dez.2012)

Guimarães, J. A. C; Oliveira, E. T.; Gracio, M. C; FernándezMolina , C. (2012). Referentes teóricos em análise documental de conteúdo no ambiente acadêmico espanhol de Biblioteconomia e Documentação - Universidade da Coruña (España), 2012.

Guimarães, E. (2001). Expressão modalizadora no discurso de divulgação científica. // Educação e Linguagem. 4: 5.

Guimarães, J. A. C. (2008). A dimensão teórica do tratamento temático da informação e suas interlocuções com o universo científico da Internacional Society for Knowledge Organization (ISKO). // Revista Ibero-americana de Ciência da Informação. 1:1.

Guimarães, J. A. C. (2009). Abordagens Teóricas em tratamento temático da informação: catalogação de assunto, indexação e análise documental. // Garcia Marco, Francisco Javier (org.). Avances y perspectivas en sistemas de información y de documentación. Zaragoza: Prensas Universitarias de Zaragoza, 2009.

Guimarães, J. A. C.; Sales, R. (2010). Análise documental: concepções do universo acadêmico brasileiro em Ciência da Informação. // Datagramazero. 11:1 (fev. 2010).

Izquierdo Alonso, M. (2000). Nuevos enfoques en el estudio del tratamiento documental de contenido desde los presupuestos de las ciencias del lenguaje. // Scire: representación y organización del conocimiento. 6:1 (enero-jun. 2000).

Izquierdo Alonso, M.; Moreno Fernández, L. M. (2009). El resumen documental: un reto didáctico. Madrid: Anabad, 2009.

Lima, L. M. (2015). O percurso discursivo da Ciência da Informação no Brasil: Uma análise discursiva à partir dos periódicos Ciência da Informação e Revista da Escola de Biblioteconomia da UFMG. 2015. Marília: Unesp.Trabalho de conclusão de curso. 2015.

Le Coadic, Yves-François. (1996). A ciência da informação. Brasília: Briquet de Lemos/Livros, 1996.

Mazière, F. (2007). A análise do discurso: história e práticas. São paulo: Parábola Editora, 2007.

Maingueneau, D. (1997). Novas tendências em análise do discurso. Campinas: Pontes,1997.

Maingueneau, D. (2008). Gênese dos discursos. São Paulo: Parábolas Editorial, 2008.

Menezes, E. M ; Silva, E. L.; Couzinet, V. (2007). A Ciência da Informação na França e no Brasil. // DataGramaZero 8: 6 (dez 2007).

Moraes, J.B.E.de (2011). A questão do aboutness no texto narrativo de ficção. Marília: Unesp. Tese Livre Docência Linguística e Documentação. 2011.

Otlet, P. (1943). Traité de documentacion: le livre surle livre: théorie et pratique. Bruxelles: Mundaneum, 1934. http://lib.ugent.be/fulltxt/handle/1854/5612/Traite_de_documentation_ocr.pdf (2016-09-19).

Orlandi, E. P. (1999). Análise de discurso: princípios e procedimentos. Campinas, SP: Pontes, 1999.

Orlandi, E. P. (2000). Discurso e leitura. 5. ed. São Paulo: Editora da Unicamp, 2000. 
Pecheux. M. (1975). Semântica e discurso: uma crítica à afirmação do óbvio. Tradução de Eni P. Orlandi [et al.]. Campinas: Editora da UNICAMP, 1975.

Pêcheux, M; Fuchs, C.(1997). A propósito da Análise Automática do Discurso: atualizações e perspectivas, 1975. // Por uma análise automática do discurso: uma introdução a obra de Michel Pêcheux / Gadet, Francaise; Hak, Tony (orgs.); tradutores Eni Pulcinelli Orlandi... [et al.). 3. ed. Campinas, SP: Editora da UNICAMP, 1997.

Pinheiro, L. V. R. (1998). Campo interdisciplinar da Ciência da Informação: fronteiras remotas e recentes. // Investigación Bibliotecológica. México. 12:25 (jun 1998) file:///C:/Users/Unesp/Downloads/ibi02508.pdf. (2013-0807).

Pinheiro, L. V. R; Loureiro, J. M. M. (1995). Traçados e limites da Ciência da Informação// Ciência da Informação. Brasil. 24:1 (fev 1995) http://revista.ibict.br/ciinf/index.php/ciinf /article/viewFile/531/483. (2013-10-18).

Pinto Molina, M. (1992). El resumen documental: principios y métodos. Madrid; Salamanca: Fundación Germán Sánchez Ruipérez; Madrid: Pirámide, 1992.
Rocha, D.; Deusdará, B . (2005). Análise de Conteúdo e Análise do Discurso: aproximações e afastamentos na (re)construção de uma trajetória. // Alea (online). 7:2 (fev 2005).

Ruiz pérez, R. (1992). El análisis documental: bases terminológicas, conceptualización y estructura operativa. Granada: Ed. Universidad de Granada, 1992

Saussure, F. (1973). Curso de linguística geral. 5. ed. São Paulo: Cultrix, 1973.

Sagredo Fernández, F.; Izquierdo Arroyo, J. M. (1983). Concepción lógico-lingüistica de la Documentación. Madrid: IBERCOM, 1983.

Sagredo Fernández, F.; Izquierdo Arroyo, J. M. (1982). Reflexiones sobre "documento": palabra/objeto (I). // Boletín Millares Carlo. 5:1 (fev.1982).

Van Dijk, T. (1972). Some aspects of text grammar: a study in theorical linguistics and poetics. La haye, Mounton. 1972.

Enviado: 2015-04-01. Segunda versión: 2016-08-03. Aceptado: 2016-10-11. 
